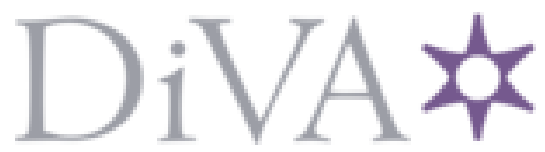

http://www.diva-portal.org

This is the published version of a paper published in Chemistry - A European Journal.

Citation for the original published paper (version of record):

Platero-Prats, A E., Bermejo Gómez, A., Samain, L., Zou, X., Martin-Matute, B. (2015)

The First One-Pot Synthesis of Metal-Organic Frameworks Functionalised with Two TransitionMetal Complexes.

Chemistry - A European Journal, 21(2): 861-866

https://doi.org/10.1002/chem.201403909

Access to the published version may require subscription.

N.B. When citing this work, cite the original published paper.

Reprinted with permission from Chemistry - A European Journal, 2015, 21 (2) 861-866. Copyright 2015 John Wiley and sons.

Permanent link to this version:

http://urn.kb.se/resolve?urn=urn:nbn:se:su:diva-113542 


\title{
The First One-Pot Synthesis of Metal-Organic Frameworks Functionalised with Two Transition-Metal Complexes
}

\author{
Ana E. Platero-Prats, ${ }^{[a, b, c]}$ Antonio Bermejo Gómez, ${ }^{[a, b]}$ Louise Samain, ${ }^{[c]}$ Xiaodong Zou, ${ }^{*[a, c]}$ \\ and Belén Martín-Matute ${ }^{*[a, b]}$
}

Abstract: The synthesis of a metal-organic framework (UiO67) functionalised simultaneously with two different transition metal complexes (Ir and Pd or Rh) through a one-pot procedure is reported for the first time. This has been achieved by an iterative modification of the synthesis parameters combined with characterisation of the resulting materials using different techniques, including X-ray absorption spectroscopy (XAS). The method also allows the first synthesis of UiO-67 with a very wide range of loadings (from 4 to $43 \mathrm{~mol} \%)$ of an iridium complex $\left(\left[\mathrm{lrCp} \mathrm{p}^{*}(\mathrm{bpydc})(\mathrm{Cl}) \mathrm{Cl}^{2-}\right.\right.$; bpydc $=2,2^{\prime}$-bipyridine-5,5'-dicarboxylate, $\quad \mathrm{Cp}^{*}=$ pentamethylcyclopentadienyl) through a pre-functionalisation methodology.

\section{Introduction}

Metal-organic frameworks (MOFs) are modular and crystalline materials ${ }^{[1]}$ amenable to chemical modification ${ }^{[2]}$ that can be used in a wide range of applications. ${ }^{[3]}$ When the intrinsic properties of MOFs are combined with those of transition metal complexes, ${ }^{[4]}$ crystalline materials with multiple potential uses, including catalysis, are created. MOFs were originally functionalised by introducing organic fragments into their linkers. ${ }^{[5]} \mathrm{Re}-$ cently, a multivariate (MTV) functionalisation was reported, through which a large number of diverse linkers bearing different organic functional groups were incorporated into MOF-5. ${ }^{[6]}$ Another versatile approach is the linker-exchange method, for example, post-synthetic exchange (PSE) and solvent-assisted linker exchange (SALE). ${ }^{[7]}$

MOFs can be functionalised with transition metal complexes through post- or pre-functionalisation strategies. Examples of post-functionalisation include metal impregnations and metallations. ${ }^{[8]}$ In the past few years, pre-functionalisation strategies

[a] Dr. A. E. Platero-Prats, ${ }^{+}$Dr. A. Bermejo Gómez, ${ }^{+}$Prof. X. Zou,

Prof. B. Martín-Matute

Berzelii Center EXSELENT on Porous Materials

Stockholm University

10691 Stockholm (Sweden)

E-mail:belen@organ.su.se

[b] Dr. A. E. Platero-Prats, ${ }^{+}$Dr. A. Bermejo Gómez, ${ }^{+}$Prof. B. Martín-Matute Department of Organic Chemistry

Stockholm University

10691 Stockholm (Sweden)

[c] Dr. A. E. Platero-Prats, ${ }^{+}$Dr. L. Samain, Prof. X. Zou Department of Materials and Environmental Chemistry Stockholm University

10691 Stockholm (Sweden)

$\left.{ }^{[+}\right]$These authors contributed equally to this work.

Supporting information for this article is available on the WWW under http://dx.doi.org/10.1002/chem.201403909. have emerged as a versatile methodology, whereby modified transition metal complexes (metallo-linkers) serve as building blocks for MOF synthesis. ${ }^{[9]}$ In this context, Lin and co-workers reported a "mix-and-match" strategy, in which a mixture of unfunctionalised linkers and metallo-linkers with matching length and connectivity was incorporated into the same MOF. ${ }^{[10]}$ Cohen, Ott, and co-workers have recently reported similar results using the PSE protocol. ${ }^{[11]}$

Despite great efforts, the synthesis of transition-metal-functionalised MOFs still presents a challenge. This is partly due to decomposition of transition metal complexes under the reaction conditions needed for MOF synthesis. The controlled synthesis of these materials functionalised with a wide range of loadings of a transition metal or with more than one transition metal complex is difficult but desirable. Furthermore, little is known about how functionalisation may change the structure of MOFs. Herein, we report the first one-pot synthesis of MOFs functionalised with one or simultaneously two transition metal complexes from their basic components (i.e., transition metal precursors, linkers, and structural metal salts) (Figure 1). The method is exemplified with the $\mathrm{Zr}^{\mathrm{IV}} \mathrm{MOF} \mathrm{UiO}-67^{[12]}$ and transition metal complexes $\mathbf{L M 1}=\left[\mathrm{IrCp}{ }^{*}(\mathrm{bpydc})(\mathrm{Cl}) \mathrm{Cl}\right]^{2-}, \quad \mathbf{L M} \mathbf{2}=$ $\left[\mathrm{Pd}(\text { bpydc }) \mathrm{Cl}_{2}\right]^{2-}$, and $\mathbf{L M 3}=\left[\mathrm{RhCp}{ }^{*}(\text { bpydc })(\mathrm{Cl}) \mathrm{Cl}\right]^{2-} \quad(\mathrm{L}=$ bpydc $=2,2^{\prime}$-bipyridine-5, $5^{\prime}$-dicarboxylate). ${ }^{[13]}$

\section{Results and Discussion}

The molecular formula of UiO-67 is $\left[\mathrm{Zr}_{6} \mathrm{O}_{4}(\mathrm{OH})_{4}(\mathrm{bpdc})_{6}\right]$, with six unique linkers (bpdc $=4,4^{\prime}$-biphenyldicarboxylate) per octahedral $\left(\mathrm{O}_{\mathrm{h}}\right)$ cavity. Functionalised analogues can then be defined as $\left[\mathrm{Zr}_{6} \mathrm{O}_{4}(\mathrm{OH})_{4}(\mathrm{bpdc})_{6-y}(\mathrm{LM} 1)_{y}\right]$, in which $y$ is the number of metallo-linkers (LM1) per $\mathrm{O}_{\mathrm{h}}$ cavity (Figure 2). As an example, $33 \mathrm{~mol} \%$ functionalisation would be represented by $y=2$ (Figure 2). The parameter $y^{\prime}$ is then defined as the intended number of metallo-linkers per $\mathrm{O}_{h}$ cavity (see the Experimental 

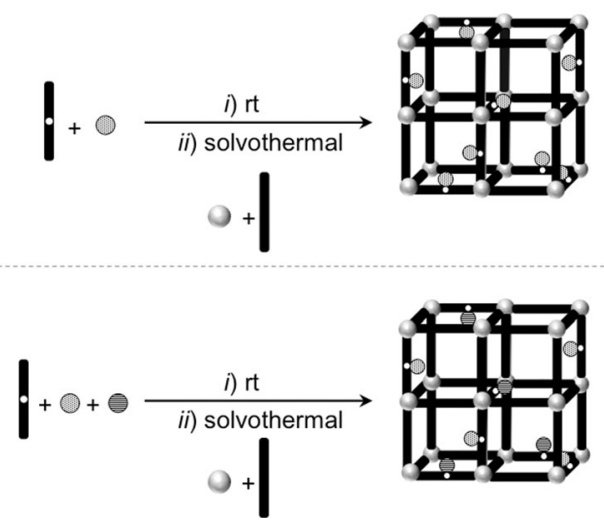

Figure 1. One-pot synthesis of UiO-67 functionalised with a) one metal complex or b) simultaneously multifunctionalised with two. The grey spheres correspond to the zirconium clusters. The dotted and striped spheres correspond to different metal complexes. The bpdc $=4,4^{\prime}$-biphenyl dicarboxylate linkers are represented as black rods and the bpydc $=2,2^{\prime}$-bipyridine-5, $5^{\prime}$-dicarboxylate linkers as black rods with white dots.

\section{Functionalised UiO-67}

$\left[\mathrm{Zr}_{6} \mathrm{O}_{4}(\mathrm{OH})_{4}(\mathrm{bpdc})_{6 \cdot x}(\mathrm{LMm})_{y}(\mathrm{bpydc})_{x-y}\right]$

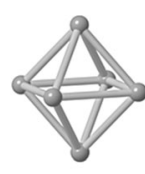

$y=0$

$=\left[\mathrm{Zr}_{6} \mathrm{O}_{4}(\mathrm{OH})_{4}\right]^{12+}$

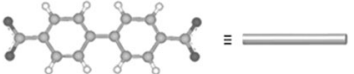

bpdc $=4,4^{\prime}$-biphenyldicarboxylate

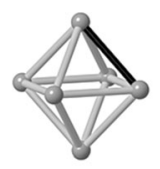

$y=0.5$

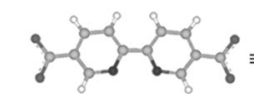

bpydc $=2,2$ '-bipyridine-5,5'-dicarboxylate

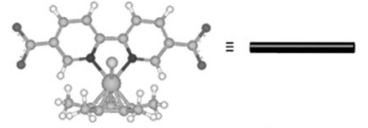

LM1 $=\left[\left(\mid \mathrm{IrCp}{ }^{*}(\text { bpydc }) \mathrm{Cl}\right) \mathrm{Cl}\right]^{2-}$
Figure 2. The UiO-67 composition is described as $\left[\mathrm{Zr}_{6} \mathrm{O}_{4}(\mathrm{OH})_{4} \mathrm{~L}_{6}\right]$, with six linkers per $\left[\mathrm{Zr}_{6} \mathrm{O}_{4}(\mathrm{OH})_{4}\right]^{12+}$ cluster. Among the six linkers $(\mathrm{L})$ are $(6-x)$ bpdc linkers, $(x-y)$ demetallated LM1 linkers (i.e., bpydc), and $y$ functionalised metallo-linkers $\mathrm{LMm}(\mathrm{m}=1-3,1=\mathrm{Ir}, 2=\mathrm{Pd}, 3=\mathrm{Rh})$. The composition of the $\mathrm{O}_{\mathrm{h}}$ cavity in UiO-67 is $\left[\mathrm{Zr}_{36} \mathrm{O}_{24}(\mathrm{OH})_{24} \mathrm{~L}_{12}\right]$. Each linker is shared by two $\mathrm{O}_{\mathrm{h}}$ cavities and the number of metallo-linkers per $\mathrm{O}_{h}$ cavity is represented by $y$.

Section). First, we evaluated the effect of several synthetic parameters in the preparation of UiO-67 functionalised with LM1 (from $\mathrm{Zr}^{\text {IV }}$ salts, $\mathrm{H}_{2}$ bpdc, and $\mathrm{H}_{2} \mathrm{LM1}$ ) $^{[10]}$ with the aim of obtaining materials with a wide range of iridium loadings. We found that the crystallinity of UiO-67 functionalised with LM1 $\left(y^{\prime}=1\right)$ is highly dependent on the amount of water used in the synthesis. By varying the number of equivalents of water (from 3 to 150 equiv per $\mathrm{ZrCl}_{4}$ ), we found that 5 equiv gave crystalline samples (Figure 3 and Table 1, entry 2, $y=0.36$; Supporting Information). Water was needed to form the $\mathrm{Zr}$ cluster. Although 1.3 equiv per $\mathrm{Zr}$ would be theoretically sufficient (in agreement with the molecular formula $\left[\mathrm{Zr}_{6} \mathrm{O}_{4}(\mathrm{OH})_{4}(\mathrm{bpdc})_{6-y}(\mathrm{LM1})_{y}\right]$,

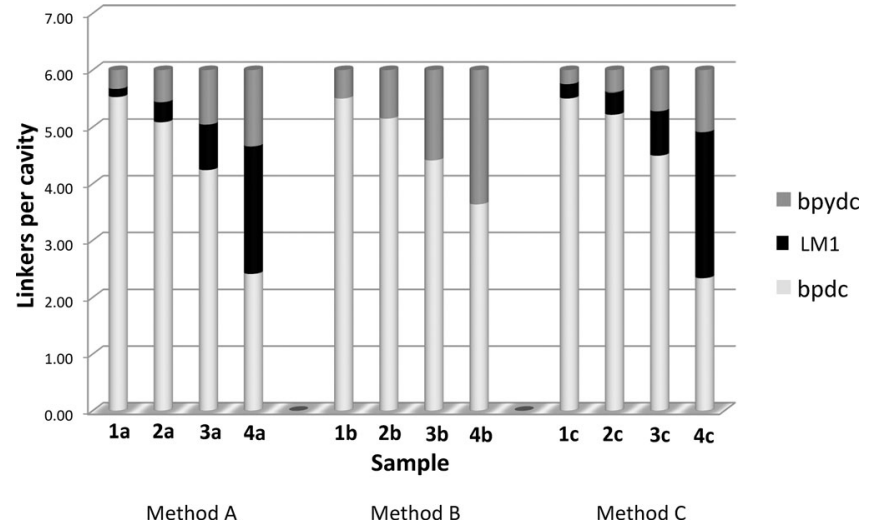

Figure 3. Linker composition per $\mathrm{O}_{\mathrm{h}}$ cavity.

Table 1. LM1 and bpydc contents determined by ${ }^{1} \mathrm{H}$ NMR spectroscopy for MOFs synthesised using Methods A, B, and C, in terms of degree of functionalisation per $\mathrm{O}_{\mathrm{h}}$ cavity $(\mathrm{y})$.

\begin{tabular}{llllllll} 
& $\begin{array}{l}\text { Sample } \\
\text { (Method) }^{[a, b]}\end{array}$ & bpdc $^{[c]}$ & bpydc $^{[c]}$ & LM1 $^{[c, d]}$ & $\begin{array}{l}\text { LM1/ } \\
\text { bpydc }^{[\mathrm{e}]}\end{array}$ & $\begin{array}{l}\text { Ir } \\
{[\mathrm{Wt} \%]^{[f]}}\end{array}$ & $\begin{array}{l}\text { Isolated } \\
\text { yield [\%] }\end{array}$ \\
\hline 1 & 1 a (A) & 5.53 & 0.33 & 0.14 & 0.42 & 1.22 & 58 \\
2 & 2 a (A) & 5.08 & 0.56 & 0.36 & 0.64 & 2.79 & 62 \\
3 & 3 a (A) & 4.24 & 0.95 & 0.81 & 0.85 & 5.53 & 65 \\
4 & 4 a (A) & 2.41 & 1.34 & 2.25 & 1.68 & 12.35 & 87 \\
5 & 1 b (B) & 5.50 & 0.50 & 0 & 0 & 0.22 & n.d. \\
6 & 2 b (B) & 5.51 & 0.85 & 0 & 0 & 0.51 & n.d. \\
7 & 3 b (B) & 4.41 & 1.59 & 0 & 0 & 1.74 & n.d. \\
8 & 4 b (B) & 3.64 & 2.36 & 0 & 0 & 5.81 & n.d. \\
9 & 1 c (C) & 5.50 & 0.25 & 0.25 & 1.00 & 1.81 & 77 \\
10 & 2 c (C) & 5.22 & 0.39 & 0.39 & 1.00 & 4.51 & 83 \\
11 & 3c (C) & 4.49 & 0.72 & 0.79 & 1.10 & 7.87 & 95 \\
12 & 4c (C) & 2.34 & 1.09 & 2.57 & 2.36 & 14.80 & 97 \\
\hline
\end{tabular}

[a] Method A: $100^{\circ} \mathrm{C}$, Teflon autoclave reactors using dry DMF as the solvent and 5 equiv of $\mathrm{H}_{2} \mathrm{O}$. Method $\mathrm{B}$ : $140^{\circ} \mathrm{C}$, Teflon autoclave reactors using dry DMF as the solvent and 5 equiv of $\mathrm{H}_{2} \mathrm{O}$. Method $\mathrm{C}$ : $100^{\circ} \mathrm{C}$, sealed microwave tube in an oil bath with stirring using dry DMF as the solvent and 5 equiv of $\mathrm{H}_{2} \mathrm{O}$. [b] Intended LM1 amounts $\left(y^{\prime}\right)$ for samples $\mathbf{1} \mathrm{a}-\mathbf{1} \mathrm{c}, \mathbf{2} \mathrm{a}-\mathbf{2} \mathrm{c}, \mathbf{3} \mathrm{a}-\mathbf{3} \mathrm{c}$, and $\mathbf{4 a - 4 c}$ were $0.5,1,2$, and 4, respectively. [c] Determined by ${ }^{1} \mathrm{H}$ NMR spectroscopic analysis of the digested samples. [d] Number of metallo-linkers (LM1) per $\mathrm{O}_{h}$ cavity $(y)$. [e] The value LM1/ bpydc was consistent for different batches. [f] Determined by ICP-AES analysis.

a slight excess of $\mathrm{H}_{2} \mathrm{O}$ was needed to obtain good reproducibility. The use of $\mathrm{ZrOCl}_{2}$ instead of $\mathrm{ZrCl}_{4}$ resulted in poorer crystallinity (see the Supporting Information). In addition, decomposition of the iridium complex was observed when different additives (e.g., formic acid or potassium carbonate) were used. To obtain a methodology that would allow higher iridium loadings, different LM1 concentrations and synthesis temperatures $\left(100^{\circ} \mathrm{C}\right.$, Method $\mathrm{A} ; 140^{\circ} \mathrm{C}$, Method B) were then tested. In all cases (Table 1, entries 1-8), crystalline materials were obtained (Figure 4). ICP-AES showed that the iridium contents were systematically lower at higher temperatures (Table 1, entries 1-4 vs. 5-8). The amount of LM1 was determined by analysing the samples by ${ }^{1} \mathrm{H}$ NMR spectroscopy after digestion under optimized conditions (i.e., $\left[\mathrm{D}_{6}\right] \mathrm{DMSO} / \mathrm{D}_{3} \mathrm{PO}_{4}$; see the Supporting In- 


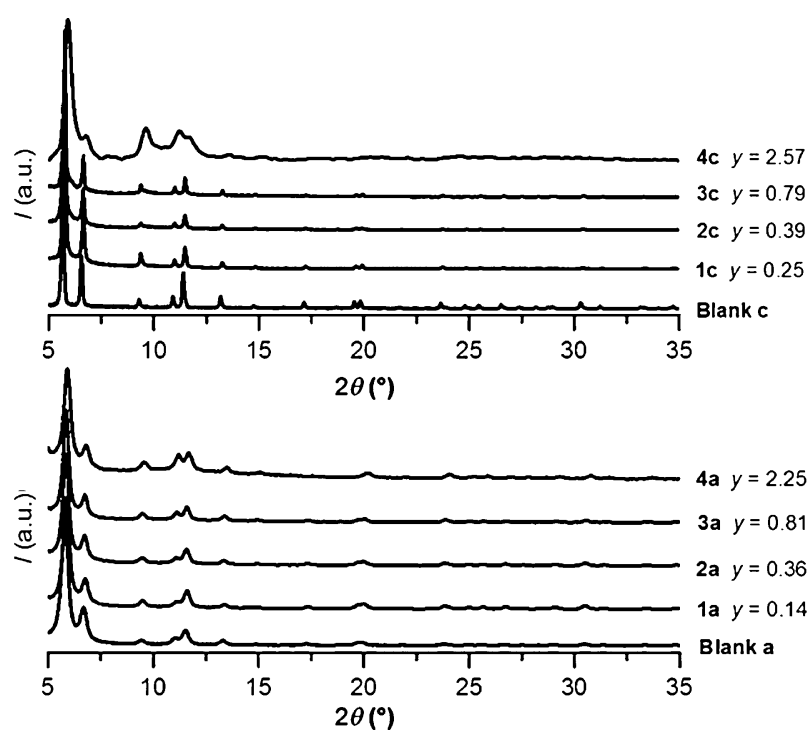

Figure 4. Powder X-ray diffraction patterns collected from samples Blank a, $1 \mathrm{a}-4 \mathrm{a}$, Blank $\mathrm{c}$, and $1 \mathrm{c}-4 \mathrm{c}$.

formation). Surprisingly, $\mathrm{H}_{2}$ bpydc was found in all digested samples. Free bpydc was formed by demetallation of LM1 during the synthesis of the MOFs, lowering the iridium metallo-linker content in the products (Table 1). ${ }^{[14]}$ Furthermore, although samples $\mathbf{1} \mathbf{b} \mathbf{-} \mathbf{4} \mathbf{b}$ contained iridium (as confirmed by ICP-AES), no LM1 was found in the digested samples by ${ }^{1} \mathrm{H}$ NMR spectroscopy (Table 1, entries $5-8$ ). Iridium is thus not present as IIII $^{\mathrm{II}}$ coordinated to bpydc but as other species, which was further confirmed by XAS (see below).
Next, we explored the effect of stirring during the synthesis of the MOF, with the aim of decreasing demetallation of LM1 and increasing the yield. The reaction mixtures were stirred in sealed vials and heated in an oil bath at $100^{\circ} \mathrm{C}$ (Method C).

Stirring resulted in a more homogeneous reaction mixture, preventing both high local concentrations of acidic species (e.g., $\mathrm{HCl}$ ) and local overheating, ${ }^{[20]}$ which may have resulted in reduced demetallation. Indeed, ${ }^{1} \mathrm{H}$ NMR spectroscopic analysis after digestion of the samples showed that $\mathbf{1} \mathbf{c}-\mathbf{4 c}$ had undergone significantly lower demetallation compared to the products obtained without stirring at the same temperature (1 a4 a) and, importantly, their crystallinity was not affected. The LM1/bpydc ratios were 1.00, 1.00, 1.10, and 2.36 for $\mathbf{1}$ c-4c (Table 1, entries 9-12; Supporting Information), compared to $0.42,0.64,0.85$, and 1.68 for 1 a-4a (Table 1 , entries $1-4$ ). This represents increases in the LM1/bpydc ratio by $138,56,29$, and $40 \%$, respectively. Furthermore, not only was the degree of functionalisation better controlled, but the yields were considerably higher (by 10-30\%). PXRD showed that Methods A and $C$ gave UiO- 67 materials with good crystallinity and a wide degree of functionalisation $(y=0-2.25)$ (Figure 4; Supporting Information). Interestingly, synthesis with stirring (1 c-3c) led to sharper PXRD peaks than without stirring, although significant peak broadening was observed for the highest functionalisation ( $4 c, y=2.57$ ). This could be explained by the formation of defects in the crystal structure of the MOF (e.g., domains).

The local environment and oxidation state of iridium was investigated by XAS. Figure 5 a shows the iridium $L_{\text {III }}$-edge $X$-ray absorption near-edge structure (XANES), which confirms incorporation of LM1 in MOFs $\mathbf{3} \mathbf{a}$ and $\mathbf{4} \mathbf{a}(\mathbf{3} \mathbf{a}, y=0.81 ; \mathbf{4} \mathbf{a}, y=2.25)$ and MOFs $3 c$ and $4 c(3 c, y=0.79 ; 4 c, y=2.57)$. The extended a)

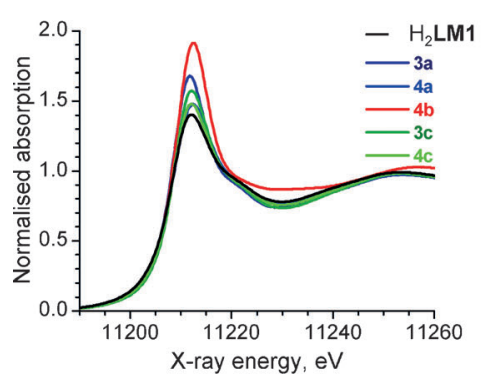

b)

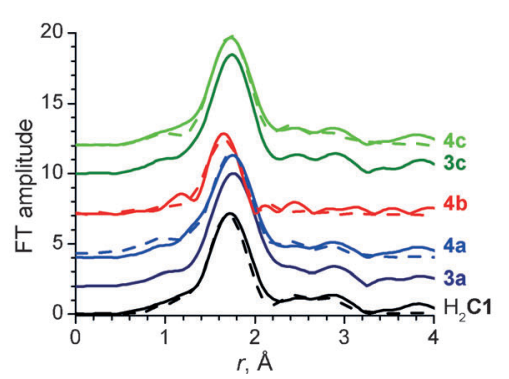

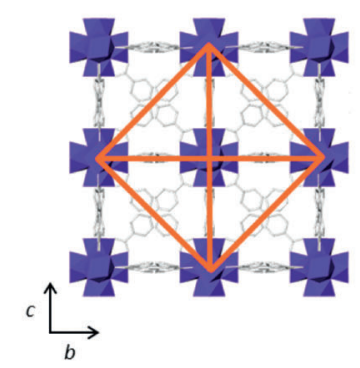

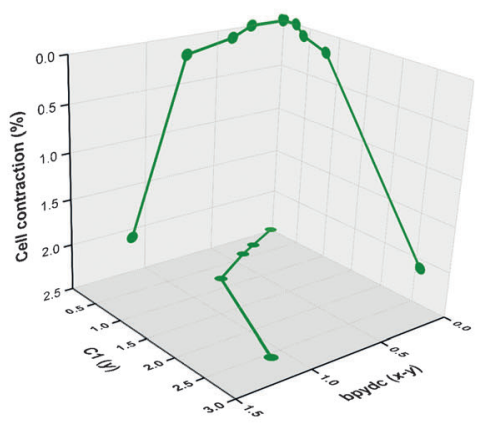

d)

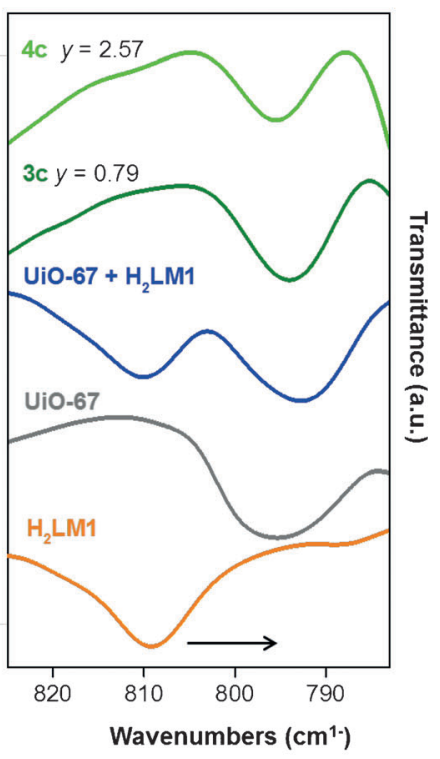

Figure 5. a) Ir $L_{1 \mid 1}$-edge XANES spectra of $\mathrm{H}_{2} \mathrm{LM} 1, \mathbf{3} \mathbf{a}, \mathbf{4 a}, \mathbf{4 b}, \mathbf{3} \mathbf{c}$, and $\mathbf{4} \mathrm{c}$. b) Experimental (solid line) and fitted (dashed line) $\mathrm{FT}\left[\chi(k) \cdot k^{3}\right]$ functions (bottom) with $\Delta k \approx 2-12 \AA^{-1}$. c) UiO-67 crystal structure and 3D plot showing the contraction of the unit cell as a function of LM1 and bpydc content for MOFs $1 \mathrm{c}, 2 \mathrm{c}, 3 \mathrm{c}$, and $4 \mathbf{c}$, determined from the PXRD data using the Pawley method. d) The ATR/FTIR spectra of $\mathrm{H}_{2}$ LM1, UiO-67, a physical mixture of UiO-67 and $\mathrm{H}_{2} \mathrm{LM} 1$, and functionalised MOFs $3 \mathrm{c}$ and $4 \mathrm{c}$. 
X-ray absorption fine structure (EXAFS) data for $\mathrm{H}_{2} \mathrm{LM} 1$ were fitted using the structure model determined by single-crystal $X$-ray diffraction (see the Supporting Information). EXAFS analyses on $\mathbf{3 a}, \mathbf{4 a}, \mathbf{3 c}$, and $\mathbf{4 c}$ confirmed incorporation of iridium exclusively in the form of LM1 (Figure $5 \mathrm{~b}$ ). In contrast, XANES and EXAFS spectra of $\mathbf{4} \mathbf{b}$ showed the presence of $\mathrm{IrO}_{2}$ as the major phase, as well as other iridium species such as $\mathrm{IrCl}_{3}$ (see the Supporting Information).

PXRD data of the samples prepared by Method C (1 c-4c) revealed a framework contraction upon functionalisation, which correlated well with the degree of functionalisation $y$ (Figure $5 \mathrm{c}$ and Table S6.3.1). A minor cell contraction $(\leq 0.2 \%)$ occurred in samples with low LM1 contents (low $y$ values) (1 c3 c, $y<0.8$ ), whereas a significant cell contraction (2.1\%) was observed for the highest degree of functionalisation with the iridium metallo-linker (4c, $y=2.57)$, as given in Table S6.3.1. This framework contraction can be explained by: (i) the different lengths of the bpdc, bpydc, and LM1 linkers, and (ii) the presence of intermolecular interactions among the LM1 subunits within the MOF $(\mathrm{C}-\mathrm{H} \cdots \pi$ and $\mathrm{C}-\mathrm{H} \cdots \mathrm{O}$, see the Supporting Information).

Attenuated total reflection Fourier-transform infrared (ATR/ FTIR) spectra of solid samples were collected for UiO-67, $\mathrm{H}_{2} \mathrm{LM1}$, and MOFs $\mathbf{1} \mathrm{c}-\mathbf{4}$ c, as well as for a physical mixture of UiO-67 and $\mathrm{H}_{2} \mathrm{LM} 1$. The aromatic $\mathrm{C}-\mathrm{H}$ stretching band of the iridium metallo-linker shifted from $810\left(\mathrm{H}_{2} \mathrm{LM} 1\right)$ to $795 \mathrm{~cm}^{-1}$ in the functionalised MOFs. This can be attributed to the different electronic environment of LM1 when coordinated to the zirconium clusters in the MOF (Figure $5 \mathrm{~d}$ ). Additionally, thermal gravimetric analysis (TGA) confirmed that LM1 has a different thermal decomposition profile when incorporated into MOFs $1 \mathrm{c}-\mathbf{4} \mathrm{c}$ (see the Supporting Information). $\mathrm{N}_{2}$ adsorption measurements confirmed that MOFs $\mathbf{1} \mathbf{c}-\mathbf{4 c}$ remained porous despite functionalisation with LM1.

Having demonstrated the beneficial effect of adding 5 equiv of water and synthesising the iridium-functionalised MOFs under stirring at $100^{\circ} \mathrm{C}$, we then attempted their synthesis by a one-pot procedure starting from the basic components (Method D, Figure 6, Table 2). The synthesis starting from commercially available $\left[\left\{1 \mathrm{rCp} \mathrm{C}^{*} \mathrm{Cl}_{2}\right\}_{2}\right]$ and $\mathrm{H}_{2}$ bpydc was successfully accomplished (see the Experimental Section) and afforded MOF 1 d (Table 2, entry $1, y=0.36$ ) with higher crystallinity than when Method $C$ was used, and in excellent isolated yield (74\%). This procedure is much simpler and more cost-effective,
Table 2. Sequential one-pot synthesis and characterisation of MOFs functionalised simultaneously with one or two transition metal complexes.

\begin{tabular}{|c|c|c|c|c|c|}
\hline & $\begin{array}{l}\text { Sample } \\
(\text { Method D) })^{[a]}\end{array}$ & bpdc & bpydc & $\mathrm{LMm}^{[\mathrm{b}, \mathrm{c}]}$ & $\begin{array}{l}\text { Isolated } \\
\text { yield [\%] }\end{array}$ \\
\hline 1 & $1 \mathrm{~d}$ & 5.28 & 0.36 & 0.36 LM1 & 74 \\
\hline 2 & $2 d$ & 5.29 & 0.12 & 0.19 LM1 + 0.40 LM2 & 84 \\
\hline 3 & $3 d$ & 4.86 & 0.34 & $0.44 \mathrm{LM} 1+0.36 \mathrm{LM} 3$ & 71 \\
\hline \multicolumn{6}{|c|}{$\begin{array}{l}\text { [a] Method D, sequential one-pot synthesis: 1) dry DMF, rt, } 24 \mathrm{~h} \text {; } \\
\text { 2) } 5 \text { equiv of } \mathrm{H}_{2} \mathrm{O}, 100^{\circ} \mathrm{C}, 40 \mathrm{~h} \text {. [b] Determined by }{ }^{1} \mathrm{H} \text { NMR spectroscopic } \\
\text { analysis of the digested samples. [c] Number of metallo-linkers (LMm) per } \\
\mathrm{O}_{\mathrm{h}} \text { cavity }(\mathrm{y}) \text {. }\end{array}$} \\
\hline
\end{tabular}

since isolation of the metallo-linker is no longer needed. The framework composition was determined as $\left[\mathrm{Zr}_{6} \mathrm{O}_{4}(\mathrm{OH})_{4}(\mathrm{bpdc})_{5.28}(\mathrm{LM} 1)_{0.36}(\mathrm{bpydc})_{0.36}\right]$ (Table 2, entry 1), similar to that of the MOF synthesised by Method $\mathrm{C}$ $\left[\mathrm{Zr}_{6} \mathrm{O}_{4}(\mathrm{OH})_{4}(\mathrm{bpdc})_{5.22}(\mathrm{LM} 1)_{0.39}(\mathrm{bpydc})_{0.39}\right]$ (Table 1, entry 10).

Taking advantage of this successful methodology, we applied the sequential one-pot route to synthesise for the first time MOFs functionalised simultaneously with two transition metal complexes, LM1 + LM2 (2 d, Ir + Pd) (Table 2, entry 2), and LM1 + LM3 (3 d, Ir + Rh) (Table 2, entry 3). Using the commercially available metal precursors $\left[\left\{\mid r \mathrm{Cp}^{*} \mathrm{Cl}_{2}\right\}_{2}\right], \mathrm{PdCl}_{2}$, and [\{RhCp* $\left.\left.\mathrm{Cl}_{2}\right\}_{2}\right]$ (Table 2), crystalline dual-functionalised materials were obtained in excellent yields (2d, 84\%; $\mathbf{3 d}, 71 \%)$. The compositions were determined after digestion as $\left[\mathrm{Zr}_{6} \mathrm{O}_{4}(\mathrm{OH})_{4}(\mathrm{bpdc})_{5.29}(\mathrm{LM} 1)_{0.19}(\mathrm{LM} 2)_{0.40}(\mathrm{bpydc})_{0.13}\right]$ for $\mathbf{2} \mathbf{d}$ and $\left[\mathrm{Zr}_{6} \mathrm{O}_{4}(\mathrm{OH})_{4}(\mathrm{bpdc})_{4.86}(\mathrm{LM1})_{0.44}(\mathrm{LM} 3)_{0.36}(\mathrm{bpydc})_{0.34}\right]$ for $\mathbf{3 d}$ (Table 2). ATR/FTIR and TGA data confirmed coordination of the metallo-linkers to the zirconium clusters in MOFs $\mathbf{1} \mathbf{d}-\mathbf{3} \mathbf{d}$, and the BET surface areas of these materials indicated good porosity (see the Supporting Information).

\section{Conclusion}

In conclusion, we have presented here the first one-pot synthesis of a metal-organic framework (UiO-67) pre-functionalised with one or simultaneously two transition metal complexes. This efficient methodology uses commercially available metal precursors ([\{IrCp* $\left.\left.{ }^{*} \mathrm{Cl}_{2}\right\}_{2}\right], \mathrm{PdCl}_{2}$, and $\left.\left[\left\{\mathrm{RhCp} \mathrm{C}^{*} \mathrm{Cl}_{2}\right\}_{2}\right]\right)$, and requires neither isolation nor purification of the metallo-linkers, resulting in shorter synthesis times and lower costs. This has been achieved by evaluating how the experimental parameters
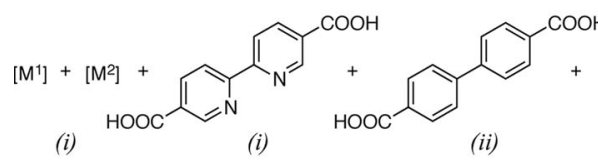

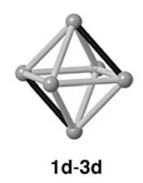

1d; $\left[\mathrm{M}^{1}\right]=\left[\mathrm{M}^{2}\right]=\left[\left\{\mathrm{l} \mathrm{r} C \mathrm{Cp}^{*} \mathrm{Cl}_{2}\right\}_{2}\right]$

2d; $\left[\mathrm{M}^{1}\right]=\left[\left\{\mathrm{IrCp}^{*} \mathrm{Cl}_{2}\right\}_{2}\right],\left[\mathrm{M}^{2}\right]=\mathrm{PdCl}$

3d; $\left[\mathrm{M}^{1}\right]=\left[\left\{\mathrm{IrCp}^{*} \mathrm{Cl}_{2}\right\}_{2}\right],\left[\mathrm{M}^{2}\right]=\left[\left\{\mathrm{RhCp} \mathrm{C}^{*} \mathrm{Cl}_{2}\right\}_{2}\right]$

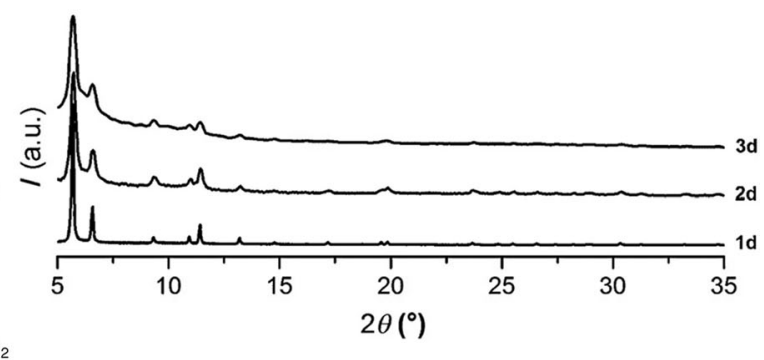

$2 \theta\left(^{\circ}\right)$

Figure 6. Sequential one-pot synthesis (Method D) of MOFs and PXRD patterns of $\mathbf{1} \mathbf{d}, \mathbf{2} \mathbf{d}$ and $\mathbf{3} \mathbf{d}$. 
(water content, temperature, and stirring) influence the MOF synthesis by means of complementary characterisation techniques (PXRD, ' $\mathrm{H}$ NMR, ICP-AES, XAS, TGA, and ATR/FTIR). Additionally, the optimised procedure allows the synthesis of UiO67 containing an unprecedentedly wide range of iridium loadings (4-43 mol\%). This study has also shown that demetallated linkers are part of the MOF structure, and that a framework contraction occurs upon functionalisation.

On the basis of the presented advantages, this sequential one-pot methodology is expected to be broadly applicable for the synthesis of new MOFs functionalised with different transition metal complexes.

\section{Experimental Section}

\section{Synthesis of (multi)functionalised UiO-67 MOFs}

Synthesis of UiO-67 functionalised with LM1 (Method C): $\mathrm{ZrCl}_{4}$ (46.6 mg, $0.2 \mathrm{mmol}, 1$ equiv), $\mathrm{H}_{2} \mathrm{LM} 1 \quad(\mathrm{zmmol})$, and $\mathrm{H}_{2} \mathrm{bpdc}$ $([0.2-z] \mathrm{mmol})$ were placed in a vial, dry DMF $(9 \mathrm{~mL})$ and water (18 $\mu \mathrm{L}, 1 \mathrm{mmol}, 5$ equiv) were added, and the vial was sealed. The mixture was stirred at room temperature for $10 \mathrm{~min}$, and then it was heated with stirring at $100^{\circ} \mathrm{C}$ in an oil bath for $72 \mathrm{~h}$. The reaction mixture was then allowed to cool down to room temperature. The solid was separated by centrifugation, activated by washing sequentially with $\mathrm{DMF}(15 \mathrm{~mL}), \mathrm{MeOH}(15 \mathrm{~mL})$, water $(15 \mathrm{~mL})$, and acetone $(15 \mathrm{~mL})$, and dried at $80^{\circ} \mathrm{C}$ in vacuum $(0.1 \mathrm{mmHg})$ for $10 \mathrm{~h}$. Note: the value $z$ is $y^{\prime}$ expressed in mmol for a reaction carried out on a $0.2 \mathrm{mmol}$ scale.

One-pot synthesis (Method D): The transition metal complex precursor(s) $(0.033 \mathrm{mmol})$ and $\mathrm{H}_{2}$ bpydc $(0.033 \mathrm{mmol})$ were placed in a microwave tube, dry DMF ( $9 \mathrm{~mL}$ ) was added, and the tube was sealed. The mixture was stirred at $\mathrm{rt}$ for $24 \mathrm{~h}$. $\mathrm{ZrCl}_{4}(0.2 \mathrm{mmol}$, 1 equiv), $\mathrm{H}_{2}$ bpdc $(0.167 \mathrm{mmol})$, and water $(1 \mathrm{mmol}, 5$ equiv) were then added. The mixture was first stirred at room temperature for $10 \mathrm{~min}$, and then heated under stirring at $100^{\circ} \mathrm{C}$ in an oil bath for $72 \mathrm{~h}$. After cooling, the solid was separated by centrifugation, washed sequentially with DMF $(15 \mathrm{~mL}), \mathrm{MeOH}(15 \mathrm{~mL})$, water $(15 \mathrm{~mL})$, and acetone $(15 \mathrm{~mL})$, and dried at $80^{\circ} \mathrm{C}$ in vacuum $(0.1 \mathrm{mmHg})$ for $10 \mathrm{~h}$.

Digestion and subsequent molecular analysis of the functionalised MOFs by ${ }^{1} \mathrm{H}$ NMR spectroscopy: Samples were suspended in a $0.1 \mathrm{M}$ solution of $\mathrm{D}_{3} \mathrm{PO}_{4}$ in $\mathrm{D}_{2} \mathrm{O} /\left[\mathrm{D}_{6}\right] \mathrm{DMSO}$ and stirred at room temperature for $5 \mathrm{~h}$ to allow digestion of the MOFs. The solution was then transferred to an NMR tube. ${ }^{1} \mathrm{H}$ NMR spectra were recorded at $500 \mathrm{MHz}$ on a Bruker Advance spectrometer using a BBO S2 probe, $5 \mathrm{~mm}$; with a z-gradient $(\mathrm{BBO}=$ broadband observe). In order to minimise the error, the parameters of the acquisition were as follows: number of scans (NS): 200, relaxation delay (D1): $5 \mathrm{~s}$.

X-ray absorption spectroscopy: Ir $L_{\| 11}$-edge XAS experiments were carried out at the 1811 beamline, MAX IV Laboratory, Lund. The spectra were recorded in fluorescence mode because of the relatively low concentrations of Ir in the samples. Data processing and analysis were performed with the Athena and Artemis software package using IFEFFIT. ${ }^{[15,16]}$ The background was removed using the AUTOBK and flattening algorithm implemented in Athena. The pre-edge background was linearly subtracted from 150 to $30 \mathrm{eV}$ below the edge and a three-term polynomial function was used for the post-edge background subtraction over the range 150 to $900 \mathrm{eV}$ above the edge. The frequency cut-off between the background and the data was set at $1.2 \AA$. The pre-edge background- subtracted spectra were normalised to the edge jump, E0, which was taken as the energy of the first inflection point on the edge, that is, the first maximum in the derivative of the absorption. The EXAFS reduced data $\chi(k)$ were Fourier-transformed into R-space over the range $2-12 \AA^{-1}$ with a $k^{3}$ weighting factor and a Hanning window, where the window sill was set at $3 \AA^{-1}$. The EXAFS function $(\chi(k))$ was then fitted to the ab initio multiple scattering XAS code FEFF in R-space. ${ }^{[17,18]}$ The phase shifts and back-scattering amplitudes were obtained from FEFF6.0 calculations on the structure of metallo-linker $\mathrm{H}_{2} \mathrm{LM} 1$ determined by single-crystal X-ray diffraction analysis. Detailed descriptions of the XAS analyses are given in the Supporting Information.

Powder X-ray diffraction: Powder X-ray diffraction (PXRD) was performed on a Panalytical X'Pert PRO diffractometer in BraggBrentano reflection geometry using $\mathrm{Cu}_{K \alpha}$ radiation $(\lambda=1.5418 \AA)$ at a power of $1800 \mathrm{~W}(45 \mathrm{kV}, 40 \mathrm{~mA})$. The PXRD data were collected using a silicon-based position-sensitive $X^{\prime}$ Celerator detector and programmed divergence and anti-scattering slits. Samples were suspended in 2-propanol and placed in zero-background sample holders. Optimised counting statistics were obtained by collecting data from the samples using a $0.017^{\circ} 2 \theta$ step scan from $5-35^{\circ}$ with an exposure time of $100 \mathrm{~s}$ per step. All measurements were performed at room temperature and ambient pressure.

Full-pattern profile-matching using the Pawley method ${ }^{[19]}$ was conducted with Materials Studio using data in the range $2 \theta=5-35^{\circ}$. The background was first refined by applying a second-order polynomial function. The profile was calculated starting from the unit cell parameters of CCDC-889530 ( $a=27.0942 \AA$, F23 space group). Unit cells and the zero-shift were first refined. The background was first refined by applying a tenth-order polynomial function. The patterns were then refined using a pseudo-Voigt profile, followed by refinement of peak asymmetry using the Finger-Cox-Jephcoat asymmetry function. Refinements of unit cell parameters, zero shift, peak asymmetry, and background were used to obtain the final profiles.

\section{Acknowledgements}

This project was supported by the Knut and Alice Wallenberg Foundation, the Swedish Research Council (VR), and the Swedish Governmental Agency for Innovation Systems (VINNOVA) through the Berzelii Center EXSELENT. B.M.-M. also thanks VINNOVA for a VINNMER grant. A.E.P.-P. was supported by the MATsynCELL project, Röntgen-Ångström Cluster. L.S. was supported by the Consortium for Crystal Chemistry (C3), RöntgenÅngström Cluster. The authors acknowledge the MAX IV Laboratory, Lund, for the use of the synchrotron facilities (Proposal 20120319). In particular, we thank Dr. Stefan Carlson for his assistance in using the 1811 beamline.

Keywords: functionalisation - metal-organic frameworks microporous materials · synthesis design · transition metal complexes

[1] a) G. Férey, Chem. Soc. Rev. 2008, 37, 191-214; b) O. M. Yaghi, M O'Keeffe, N. W. Ockwig, H. K. Chae, M. Eddaoudi, J. Kim, Nature 2003, 423, 705-714.

[2] a) P. Horcajada, F. Salles, S. Wuttke, T. Devic, D. Heurtaux, G. Maurin, A. Vimont, M. Daturi, O. David, E. Magnier, N. Stock, Y. Filinchuk, D. Popov, C. Riekel, G. Férey, C. Serre, J. Am. Chem. Soc. 2011, 133, 17839-17847; 
b) M. Eddaoudi, J. Kim, N. Rosi, D. Vodak, J. Wachter, M. O'Keeffe, O. M. Yaghi, Science 2002, 295, 469-472.

[3] a) J. F. Van Humbeck, T. M. McDonald, X. Jing, B. M. Wiers, G. Zhu, J. R Long, J. Am. Chem. Soc. 2014, 136, 2432-2440; b) P. Valvekens, F. Vermoortele, D. De Vos, Catal. Sci. Technol. 2013, 3, 1435-1445; c) V. Pascanu, Q. Yao, A. Bermejo Gómez, M. Gustafsson, Y. Yun, W. Wan, L. Samain X. Zou, B. Martín-Matute, Chem. Eur. J. 2013, 19, 17483-17493; d) A. E. Platero-Prats, N. Snejko, M. Iglesias, A. Monge, E. Gutiérrez-Puebla, Chem. Eur. J. 2013, 19, 15572 -15582; e) P. Horcajada, T. Chalati, C. Serre B. Gillet, C. Sebrie, T. Baati, J. F. Eubank, D. Heurtaux, P. Clayette, C. Kreuz, J.-S. Chang, Y. K. Hwang, V. Marsaud, P.-N. Bories, L. Cynober, S. Gil, G. Férey, P. Couvreur, R. Gref, Nat. Mater. 2010, 9, 172-178; f) N. L. Rosi, R. Eckert, M. Eddaoudi, D. T. Vodak, J. K. Kim, M. O'Keeffe, O. M. Yaghi, Science 2003, 300, 1127-1129.

[4] J. Hartwig, in Organotransition Metal Chemistry: From Bonding to Cataly sis, (Ed.: H. Baltes), University Science Books, Sausalito, California, 2010.

[5] a) Z. Wang, S. M. Cohen, J. Am. Chem. Soc. 2007, 129, 12368-12369; b) J. S. Seo, D. Whang, H. Lee, S. I. Jun, J. Oh, Y. J. Jeon, K. Kim, Nature 2000, 404, $982-986$.

[6] H. Deng, C. J. Doonan, H. Furukawa, R. B. Ferreira, J. Towne, C. B. Knobler, B. Wang, O. M. Yaghi, Science 2010, 327, 846-850.

[7] a) O. Karagiaridi, W. Bury, J. E. Mondloch, J. T. Hupp, O. M. Farha, Angew. Chem. Int. Ed. 2014, DOI: 10.1002/anie.201306923; Angew. Chem. 2014 DOI: 10.1002/ange.201306923; b) T. Li, M. T. Kozlowski, E. A. Doud, M. N. Blakely, N. L. Rosi, J. Am. Chem. Soc. 2013, 135, 11688-11691; c) M. Kim J. F. Cahill, Y. Su, K. A. Prather, S. M. Cohen, Chem. Sci. 2012, 3, 126-130.

[8] Selected examples: a) H. Fei, S. M. Cohen, Chem. Commun. 2014, 50, 4810-4812; b) W. Morris, B. Volosskiy, S. Demir, F. Gándara, P. L. McGrier, H. Furukawa, D. Cascio, J. F. Stoddart, O. M. Yaghi, Inorg. Chem. 2012, 51,6443-6445; c) F. Carson, S. Agrawal, M. Gustafsson, A. Bartoszewics, F. Moraga, X. Zou, B. Martín-Matute, Chem. Eur. J. 2012, 18, 1533715344 ; d) A. M. Shultz, A. A. Sarjeant, O. K. Farha, J. T. Hupp, S. T. Nguyen, J. Am. Chem. Soc. 2011, 133, 13252-13255; e) E. D. Bloch, D. Britt, C. Lee, C. J. Doonan, F. J. Uribe-Romo, H. Furukawa, J. R. Long O. M. Yagui, J. Am. Chem. Soc. 2010, 132, 14382-14384; f) L. Ma, J. M. Falkowski, C. Abney, W. Lin, Nat. Chem. 2010, 2, 838-846.
[9] Selected examples: a) C. Wang, K. E. deKrafft, W. Lin, J. Am. Chem. Soc 2012, 134, 7211-7214; b) F. Song, C. Wang, W. Lin, Chem. Commun. 2011, 47,8256-8258; c) O. K. Farha, A. M. Shultz, A. A. Sarjeant, S. T. Nguyen, J. T. Hupp, J. Am. Chem. Soc. 2011, 133, 5652-5655; d) K. Oisaki, Q. Li, H. Furukawa, A. U. Czja, O. M. Yagui, J. Am. Chem. Soc. 2010, 132, 9262-9264; e) K. C. Szeto, K. P. Lillerud, M. Tilset, M. Bjørgen, C. Prestipino, A. Zecchina, C. Lamberti, S. Bordiga, J. Phys. Chem. B 2006, 110, 21509-21520; f) R. Kitaura, G. Onoyama, H. Sakamoto, R. Matsuda, S.-i. Noro, S. Kitagawa, Angew. Chem. Int. Ed. 2004, 43, $2684-$ 2687; Angew. Chem. 2004, 116, 2738- 2741.

[10] C. Wang, Z. Xie, K. E. deKrafft, W. Lin, J. Am. Chem. Soc. 2011, 133, $13445-13454$.

[11] S. Pullen, H. Fei, A. Orthaber, S. M. Cohen, S. Ott, J. Am. Chem. Soc. 2013, 135, 16997-17003.

[12] J. H. Cavka, S. Jakobsen, U. Olsbye, N. Guillou, C. Lamberti, S. Bordiga, K. P. Lillerud, J. Am. Chem. Soc. 2008, 130, 13850-13851.

[13] Selected examples of similar complexes used in catalysis: a) N. Ahlsten, A. Bermejo Gómez, B. Martín-Matute, Angew. Chem. Int. Ed. 2013, 52, 6273-6276; Angew. Chem. 2013, 125, 6393-6396; b) S. Hansen, M. Klahn, T. Beweries, U. Rosenthal, ChemSusChem 2012, 5, 656-660; C) S. H. Lee, K. Won, H.-K. Song, C. B. Park, Small 2009, 5, 2162-2166.

[14] Recently, bpydc linkers have been proved to act as Lewis basic sites: L. Li, S. Tang, C. Wang, X. Lv, M. Jiang, H. Wu, X. Zhao, Chem. Commun. 2014, 50, 2304-2307.

[15] B. Ravel, M. Newville, J. Synchrotron Radiat. 2005, 12, 537-541.

[16] M. Newville, J. Synchrotron Radiat. 2001, 8, 322-324.

[17] B. Ravel, J. Synchrotron Radiat. 2001, 8, 314-316.

[18] J. Rehr, R. Albers, S. Zabinsky, Phys. Rev. Lett. 1992, 69, 3397-3400.

[19] G. S. Pawley, J. Appl. Crystallogr. 1981, 14, 357-361.

[20] We thank the referee for his/her suggestions.

Received: June 11, 2014

Published online on November 3, 2014 